\title{
Flipping the Classroom: A Pedagogical Approach to Applying Clinical Judgment by Engaging, Interacting, and Collaborating with Nursing Students
}

\author{
Eva Hava Peisachovich ${ }^{1}$ (Assistant Professor), Susan Murtha ${ }^{1}$, Andria Phillips ${ }^{1} \&$ Gal Messinger $^{2}$ \\ ${ }^{1}$ School of Nursing, York University, Toronto, Canada \\ ${ }^{2}$ Seneca College, Toronto, Canada \\ Correspondence: Eva Hava Peisachovich. Address: School of Nursing, York University, Toronto, Ontario, Canada, \\ M3J 1P3, Canada. Tel: 1-416-736-2100 (ext. 33931). E-mail:peva@yorku.ca
}

Received: September 22, 2016

Accepted: October 5, 2016

Online Published: October 7, 2016

doi:10.5430/ijhe.v5n4p114

URL: http://dx.doi.org/10.5430/ijhe.v5n4p114

\begin{abstract}
The flipped-classroom format offers students opportunities for engagement and ownership of learning by enabling them to make sense of their views and perspectives and connect their personal and professional experiences. Student engagement and the infusion of active learning are core concepts of the educational process; given the present generation of students' exhibited preference for digital literacy, experiential learning, interactivity, and immediacy, technology is increasingly being integrated into higher education milieus to enhance student involvement and knowledge attainment. Combined with the changing curriculum needs in nursing education today, a core course in the undergraduate program of an Ontario university was recently redesigned through implementation of a flipped-classroom format; experiential teaching/learning approaches were integrated to provide a greater opportunity for application of clinical judgment. The flipped-classroom format included prerecorded lecture modules, online forums and quizzes, unfolding-case studies, a classroom student-response system, and lab activities. Outcomes and recommendations are provided on the basis of this implementation.
\end{abstract}

Keywords: Flipped classroom, Experiential-education methodology, Higher education, Nursing education, Course redesign, Transformative teaching/learning practices

\section{Introduction}

Current scholarship proposes a vast range of theoretical solutions intended to both address and improve the ways teachers teach and students learn. Yet, studies still suggest that students are not learning the complex-reasoning skills required to develop professional competence post graduation (Benner, Tanner, \& Chesla, 2009; Peisachovich, 2016a). This paradox emphasizes the need to integrate suitable pedagogical approaches within higher education settings in order to better prepare students for success after graduation. Developing complex-reasoning skills is foundational within nursing education, given the need for students to meet the evolving health-care needs of patients with increasingly complex conditions and diagnoses (Peisachovich, 2015a; Sherwood \& Horton Deutsch, 2012; Tanner, 2006).

It is well documented that passive learning deprives students of rich educational experiences and decreases levels of stimulation in the context of knowledge application (Bergmann \& Sams, 2012; Jeffries, 2012; Peisachovich, 2016b). Moreover, it has been suggested that an average learner's attention span declines after the first ten minutes of a lecture (Hartley \& Cameron, 1967; Pashler, 1998; Wilson \& Korn, 2007) and that a learner only remembers 20\% of content delivered during a lecture (MacManaway, 1970; Stuart \& Rutherford, 1978). These statistics reinforce the potential benefits of engaging students in learning by applying experiential-education approaches that encourage reflection and knowledge acquisition through active learning. The issue faced by many faculty members, however, is where to find the time during their lecture to engage students in active learning. There are many factors that influence a learner's attention; flipping the classroom is one approach that creates opportunities to hold students' attention.

Although most of today's students are technologically savvy, current studies suggest that a significant portion of students lack critical-thinking and analysis skills, complex-reasoning skills, and communication skills, all of which 
are at the core of higher education (Jeffries, 2012; Peisachovich, 2016b). Nursing educators and administrators identify this skill deficiency as a problem, given the complexity of patients' health-care needs. Moreover, the lack of these skills has led to higher rates of unemployment and overall lower lifestyle satisfaction (European Centre for the Development of Vocational Training, 2014).

Ongoing research identifies current deficiencies in educational models/teaching practices (Jeffries, 2012; Mitchell et al, 2016; Peisachovich, 2015a, 2016a, 2016b) and indicates the need to develop innovative educational models to support today's diverse generation of students. For example, traditional lectures are generally ineffective for teaching behavioural skills, inspiring interest in a subject, or even changing attitudes or values (Bligh, 2000). Therefore, teaching solely based on PowerPoint presentations tends to contribute to students becoming disengaged or being distracted by their personal devices. One way to meet the learning needs of students is through the application of creative and diverse teaching/learning practices such as embedding active and interactive methods to keep students engaged and stimulated (Freeman et al, 2014). Thus, asking the students to participate during a lecture-for example, by solving a problem, answering a question, or discussing content with a classmate or a group — can lead to stronger student engagement and improved results. In high-enrolment courses, utilizing a flipped format and having the students use their own personal devices can facilitate such interactive methods.

The flipped-classroom format, in which traditional lectures are video-recorded and assigned as "homework" to be viewed before each class, provides increased class time for meaningful experiential-education, active-learning exercises. The adoption of the flipped-classroom format allows for student engagement and affords students ownership of their learning processes; it enables students to share views and perspectives and link the content to their personal and professional experiences-particularly in high-enrolment classroom environments. In short, this methodology provides opportunities to apply clinical judgment and to develop the ability to "think like a nurse" (Tanner, 2006).

This paper discusses the implementation of the flipped classroom as part of a first-year course redesign in a baccalaureate nursing program. The purpose of this paper is to provide an overview of the flipped-classroom format (applied as part of a course redesign), outline the findings of the learning that occurred during this process, provide recommendations based on the results, and share the experiences from this project with those wanting to develop or redesign a course to transform the learning experiences of their students.

\section{Methods}

The course redesign was made possible through a curricular innovation grant at an Ontario university, which provided faculty with opportunities to transform their pedagogical practice by employing innovative teaching methods in their classrooms. In the fall of 2015, HH NURS 1543 Health Assessment, a required one-term course for first-year nursing students in a Second-Degree Entry program, was redesigned using the flipped-classroom format; the intended purpose of this redesign was to transform the educational experiences of students through enhanced in-class activities and active participation facilitated by technology (using Top Hat, a platform for engaging students via their own personal devices). The redesign also addressed the need to expose students to realistic, complex situations in order to increase application of clinical judgment and higher order thinking and enhance students' confidence - both in the care they provide to patients and their families and in their transition to nursing practice. Further, the flipped-classroom format presents opportunities for open-ended experiences and, thus, enhances collaborative practices between teachers and learners.

The implementation of the flipped-classroom approach is particularly timely given the curriculum changes currently taking place in Canada associated with the expectations of the new nursing registration exam, the NCLEX-RN. As of January 2015, nursing graduates in Ontario are required to write and pass the NCLEX-RN registration exam (adapted from the US nursing registration examination) as part of their transition to nursing practice in Canada. The new question format and computer adaptive-testing approach of the NCLEX-RN requires changes in course design in order to provide students an opportunity to familiarize themselves with this style of evaluation.

\subsection{Course and Program Description}

The Second Degree Entry program is a condensed and continuous six-semester program, which allows students to complete their BScN in two calendar years. HH NURS 1543, a core course in the first term of the program, exposes students to basic principles and components of comprehensive health assessment across the lifespan (but with an emphasis on adulthood); it focuses on developing skills in communication, interviewing, and assessment of the physical status of the individual, and explores physical, psychosocial, sexual, cultural, spiritual, familial, community, 
and environmental health concerns. Students learn about expected and unexpected circumstances and about identifying at-risk behaviours.

In the eight years prior to this course redesign, the course director delivered HH NURS 1543 using a traditional lecture format, which consisted of 90-minute lecture, 30 minutes of an active-learning activity, and a 10 minute, preor post-lecture, open-book quiz or case-study application in each class. To evaluate students' learning and application of course content, $75 \%$ of the final grade was distributed across three exams, which were equally divided into multiple-choice and short-answer questions. A reflection paper accounted for the remaining $25 \%$. A comparison of the evaluation distribution for the original and redesigned models can be seen in Table 1 .

Table 1. Learning evaluation comparison between traditional model and redesigned model

\begin{tabular}{lll}
\hline Assignment/Test & $\begin{array}{l}\text { Percentage of Course Grade } \\
\text { (Traditional Model) }\end{array}$ & $\begin{array}{l}\text { Percentage of Course Grade } \\
\text { (Redesigned Model) }\end{array}$ \\
\hline Midterm \#1 & $25 \%$ & $25 \%$ \\
Midterm \#2 & $25 \%$ & $25 \%$ \\
Online quizzes & - & $5 \%$ \\
Case-scenario assignments & - & $10 \%$ \\
Participation using Top Hat & - & $10 \%$ \\
Reflective paper & $25 \%$ & - \\
Final exam & $25 \%$ & $25 \%$ \\
\hline
\end{tabular}

\subsection{Redesigning HH NURS 1543 to Flipped-Classroom Format}

The redesigned course was delivered to 148 students over 12 weeks; these students were divided into 30 groups, consisting of approximately five members each. The redesigned, flipped model for the classroom was devised with the support of the IT team at the university and with Moodle, an open-source course-management system. In the redesigned course, in-class lectures were replaced with online self-paced videos. The goal of these videos was to provide students with fundamental concepts prior to class so they could employ their knowledge during class activities. Students prepared for the lesson in advance by watching the prerecorded videos and completing the assigned readings. This flipped-classroom approach provided more time in class for the instructor and two teaching assistants (TAs) to engage with students in an interactive manner. The 120-minute, in-class component of the course was dedicated to interactive activities designed to promote critical thinking and engaged discussions. These activities included (a) clinical-case study, (b) Top Hat classroom audience response, and (c) clinical-environment simulation through role-play and improvisation. Following each class, students participated in a two-hour lab that used high-technology simulations that reinforced content taught in that day's class.

A brief description and discussion of each of the teaching tools, as well as (where applicable) how each facilitated assessment, is provided next and summarized in Figure 1.

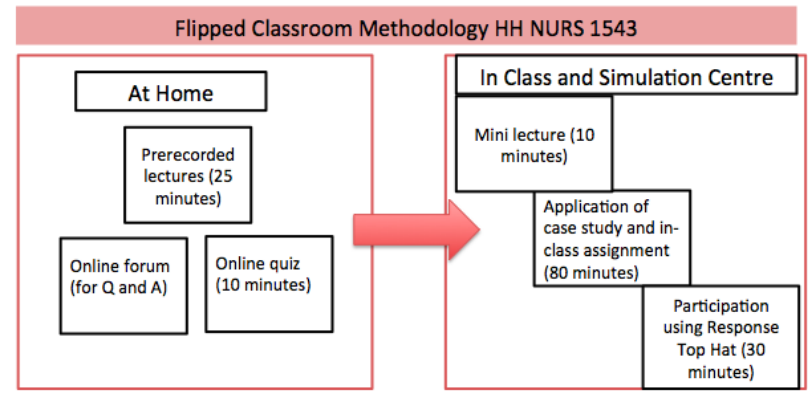

Figure 1. HH NURS 1543 flipped-classroom methodology

\subsubsection{Online and Preparatory Content}

Camtasia Studio video-recording and hosting software was used to record 12 learning modules, each covering a lesson's objectives and the main points of the content to be covered for the day. These 30 to 45 minute video modules were uploaded to the course website, and a URL was provided to students so they could view the 
prerecorded lectures prior to attending each class. These were available prior to the course start date, accessible through both the Moodle course webpage and the links provided on the course syllabus; students were thus able to access all modules or recordings at any time over the course of the term.

\subsubsection{Online Forums}

Online forums were created on the course webpage to align with each module and afford students an opportunity to pose questions and seek clarification about the course content, assigned readings, and other associated material. The instructor and two TAs were each assigned 10 groups (50 students) to interact with in order to ensure that students received effective feedback in a timely manner. These online forums also provided faculty and students with opportunities to obtain and answer questions during class - a particularly valuable approach for students who do not want to put up their hands in class.

\subsubsection{Online Quizzes}

After watching the online video modules and completing assigned readings but before attending each class, students were to complete an online quiz. There were a total of ten quizzes, each of which aligned with materials covered in a single module ( 2 to 11, inclusive). Each quiz was created on Moodle, consisted of five questions, and was available 24 hours prior to each module. Once students accessed the quiz, they had ten minutes to complete it. Questions were posed in various formats, including multiple choice, word answer, numeric answer, matching, and sorting. The formats of these quiz questions were designed to align with those of NCLEX-RN questions, so that students could familiarize themselves with this type of evaluation methodology. The students' results and the rationale for the quiz were provided after the quiz had closed. The quizzes were graded and accounted for $5 \%$ of the course's total score.

\subsubsection{Clinical-Case Scenario}

A clinical-case scenario, aligned with the lesson's learning objectives, was presented in each class to allow students to experience the reality and complexity of caring for clients and their families. A brief introduction for each case scenario-including a synopsis of the chief reason for seeking nursing care and of the client's demographics, such as age, gender, socioeconomic status - was provided on Moodle prior to each lesson. In class, the students sat in their groups of five to work on the unfolding scenario together. As the scenario unfolded, students were presented with questions designed to elicit discussion with the collective, the instructor, the TAs, and fellow students in their group. A 90-minute block of time was dedicated to this activity. The case scenario was presented through role-play between the instructor and the TAs. One TA would play the client and the other would play the client's family member or a healthcare provider. The students interacted with the client - through the use of different formats, such as Top Hat, or in-person client interviews - and offered suggestions for conducting a health history and physical to the healthcare provider. The students' task was to collect the associated clinical findings. The case unfolded to provide students with a deeper understanding of client-centred care, particularly in the areas of communication and interaction with the client. As the case unfolded, the class was presented with a new or different issue, which they had to make decisions about or find solutions for; these unfolding cases encouraged students to discuss options with their group members. The students were to complete the series of questions associated with each clinical case as it unfolded in class and submit their answers and recommendations on Moodle. Throughout the class, as the case unfolded, students were given the same series of questions to answer as a group and were asked to submit responses, including recommendations for care and/or changes to care, in hard copy.

The groups had seven days to complete and submit these case-scenario assignments via Moodle for review by their assigned instructor or TA. The purpose of these assignments was to assess students' ability to both integrate theory and practice within the context of a clinical scenario and to critically reflect and analyze the care that was provided. Ten clinical-case scenarios, which accounted for $10 \%$ of the final grade, were presented in class over the course of the term.

\subsubsection{Participation Using Classroom Response System}

The final 30 minutes of in-class time were used to assess formative knowledge, using an interactive teaching platform and classroom response system, Top Hat. Top Hat, a cross-platform software application, provides students the ability to connect with the instructor and with each other via smartphones, tablets, laptops, desktops, and SMS cellphones. The system allowed the instructor to track and customize grading structure, attendance, and performance. Further, its ability to pose questions in six different formats-multiple choice, click-on target, numeric answers, word answers, sorting, and matching - mirrors the NCLEX-RN experience, which allowed the instructor to provide students with repeated exposure and practice; during each session, the instructor would ask ten such questions. Top Hat allowed the instructor to immediately tabulate and display the students' responses. This elicited discussion of the 
responses and inconsistencies or incorrect answers and afforded the instructor an opportunity to explain and clarify and, thus, provide students with a deeper understanding of the content. The Top Hat participation component accounted for $10 \%$ of the final course grade, with participation during each of ten lectures contributing $1 \%$.

\subsubsection{Simulated Clinical Environment}

A two-hour lab followed the in-class lesson. This environment allowed students to apply knowledge gained in class to a simulated clinical arena and to practise skills learned with a high-technology simulator or manikin. The lab time was divided into ten, 10-minute stations. Each station focused on different skills including a focused physical assessment of a client, in which students interacted with a standardized patient to practice interviewing and gathering of subjective information. There was no grade associated with these activities.

\subsection{Course Implementation}

The class met for a two-hour class each Wednesday morning that was followed by a two-hour lab in a simulated clinical environment. At the beginning of the term, the students were provided with a comprehensive course syllabus that outlined course objectives and learning outcomes and explained the motivation for the redesign. Prior to beginning the course, students were provided with a video discussing the application of the flipped-classroom format and expectations of the course redesign. They were also instructed to purchase Top Hat classroom response software; on the first day of class, to familiarize the students with using Top Hat, this software was used to survey students in class regarding their general demographics and their experiences with flipped-classroom format. (We learned that only $2 \%$ ( 3 out of 148 ) of the students had been previously exposed to this format.)

The instructor and two teaching assistants supported the in-class component and four clinical instructors supported the lab component. The teaching assistants, who were nurses themselves, were highly trained and were able to provide thoughtful and constructive feedback to students. In addition to grading their students' work, the course director and 2 TAs (a) supervised between 48 to 50 students each and provided feedback on their in-class assignments, (b) facilitated online forum discussions, and (c) assisted with the creation of case studies and audience-participation questions for purposes of in-class engagement. The redesigned format required that the TAs commit between 10 to 12 hours per week (about 120-140 hours per term) to the course. The TAs attended classes, held office hours, communicated with students, and assisted with the preparation and grading of assignments. It was ensured that out-of-class time per credit hour was consistent with the university guidelines. Although specific hours were not tracked, we estimate that the time commitment required to create content for this course represents an approximately $200 \%$ increase (50\% for the teaching assistant and $150 \%$ for faculty) over the time commitment required by the traditional lecture-based approach delivered in previous years.

\section{Results}

This flipped-classroom format impacted students' grades: In comparison to the previous year, the students' grades were significantly higher. The final exam, which measured knowledge application and content analysis and synthesis, was identical to the one used the previous year, when the course was offered in the traditional manner, yet students' performance improved by 5.5\% over the previous year (65\% to $70 \%$ in 2014 and $70.5 \%$ to $80.5 \%$ in 2015). This increase underscores the impact that active learning can play in education's future. The ability to apply knowledge and analyze content learned allowed students to demonstrate an increased level of problem-solving skills and clinical judgment, both during in-class activities and in the simulated clinical environment. Faculty members involved in co-teaching this course in the simulated clinical setting observed that students were able to develop and apply reasoning skills, as evidenced by their approach in given client situations.

Students also demonstrated enhanced professional competence through their performance in the simulated clinical environment, as illustrated through their communication and interactions with simulated patients under their care. The TAs supporting the clinical-simulation environment commented that many students were able to respond to client questions with increased confidence and were able to seek clarification from the client to ensure appropriate care was provided. These behaviours also reinforce students' levels of self-efficacy and assertiveness, which are required skills in developing clinical judgment and reasoning proficiency.

The classroom environment became a collaborative and mutual teaching-learning milieu, in which the collective could share and learn from each individual's experiences. Both students and faculty commented on this. One TA described her experience in the classroom as "eye opening," noting the flipped-classroom format allowed her "to apply and transfer her clinical knowledge in a more realistic fashion." Similarly, a student commented, "Client encounters I was exposed to in class led me to better understanding of the different ways to approach and communicate with clients and their families in the actual clinical arena." 
The implementation of new and innovative methodologies such as the flipped classroom requires time for preparation. The TAs commented that the time they put into preparing material for in-class activities, grading, and providing continuous feedback - both on assignments and within the online forums - had not been anticipated prior to initiating the course. This preparation time included (a) capturing or recording of the lectures, (b) preparation of online quizzes, (c) new formatting of exams, (d) creating clinical-case scenarios and associated materials, including scripts for the role-play and improvisation, (e) creating active-learning exercises to be used with the classroom audience response, and (f) grading assignments and examinations.

Although the clinical-case scenarios utilized in class were well received by students, the online video modules were not. Many students indicated that they wanted more "lecture" during face-to-face encounters and wanted the "rawness" of the instructor's clinical experiences. Students described both their positive and negative experiences with the methodology, with one commenting, "It was a little hard to get used to in the beginning . . . but then, as I got going with it, I realized that the flipped class was actually facilitating my learning."

Many students commented on the amount of preparation time they needed to commit to this course in order to listen to online lectures, complete reading for the upcoming in-class interactive session, write the online, pre-class quiz, and complete an assignment following each in-class session. One student noted, "We were used to just going to class and not having to do so much preparation for the class ... and with this [flipped classroom] you actually have to do reading or watch the [lecture modules], you actually have to prepare for the class."

\section{Discussion}

The course redesign contributed to enhanced learning and improvement in levels of autonomy, professional competence, and motivation, as evidenced by students' attendance levels, preparedness for in-class interactions, and levels of participation during class discussions. Students applied skills such as self-directed learning by independently exploring new content and developing skills to be applied during in-class activities; they demonstrated these skills by asking relevant questions in the online forum and researching diagnoses and associated factors prior to interacting with the client case they discussed in class. Students and instructors (including TAs) developed mutual understanding through in-class discussions and the sharing of experiences. The process led to further development of professional competence, as it enhanced students' ability to identify their strengths and weaknesses regarding knowledge of the course content and ability to apply it to realistic clinical milieus. The increased ability to self-assess and thus ameliorate weaknesses improved performance on exams. That said, there are limitations to this type of course format, and there is room for improvement on the course design.

A limitation of the study is that the relationship between the course format and the students' grades is correlational; that is, although students achieved higher scores in this course over those of the previous year, it is unclear whether they performed better in the course because the revised format required that they do more work overall or because they started learning prior to attending class. Although this increase in final grades was substantial in this course, the findings cannot be generalized to other courses or contexts given the differences in course experiences and expectations. Further, an investigation of the impact of the changes to course and evaluation formats on students' performance on the NCLEX-RN was beyond the scope of the study. Additional studies are recommended to investigate this with other cohorts within higher education.

On the basis of the instructors' experiences and the feedback provided by students in the course, the following recommendations are offered to others who wish to use this type of flipped-classroom format.

1. Avoid creating a course that requires substantially larger time commitments from both the professor and the students. For example, this issue could have been ameliorated in the study by reducing the length of prerecorded online learning modules or lectures and by dividing the content into shorter sections. Find a balance between what students need to do to learn the content and how much content needs to to be taught to them.

2. Consider the increased time commitment required of faculty in preparing material and associated content. This can be minimized by using collaborative approaches such as sharing and recycling content and getting an early start in preparation for the course. Leaving preparation of material to the last minute can be overwhelming.

3. When implementing the flipped-classroom format, take faculty time and resources into consideration. Factor in the resources required to create and supply this form of course delivery, such as IT support and software to embed the methodology.

4. The adoption of the flipped-classroom format has the potential to support not only nursing-program curriculum requirements but also students' success on the registration exam and in transitioning to practice. An examination of 
the impact of this form of experiential-education methodology on NCLEX-RN success rates is, thus, worth considering.

It is obvious that digital educational technology can play an important role in shaping a classroom. Although the use and application of the Internet has changed the experiences of students, it was the relatedness and interaction between instructors and students that contributed to the richness of the learning experiences that developed for all those involved. Moreover, the application of the content was different in this flipped-classroom model; both instructors and students were able to explore content that provided learning and teaching opportunities, which they would have been unable to do if the instructors' time had been used solely to deliver three-hour lectures.

\section{Conclusion}

Overall, the findings provide a useful contribution to the growing literature on flipped-format classroom instruction and active learning in higher education. While the findings, including increased grades, underscore the promise of this approach, it is important to consider that the flipped classroom is neither for every course nor for every student population.

When making a change in the curriculum, success is often dependent on the manner in which the change is implemented. While the methodology required a substantial time and resource commitment up front, future course modifications are expected to take less time to create and implement. Although studies have been conducted regarding flipped-classroom format in the past, this is one of the few studies to examine current flipped-classroom methodology in high-enrolment courses, in which students are engaged through different kinds of active learning in the classroom. The flipped-classroom methodology allowed the author, who is both a teacher and a researcher, to reinforce the connection between these two components and, by so doing, to contribute to the deeper learning of the students in this core course.

\section{Acknowledgement}

The York University Academic Innovation Fund Grant

\section{Conflict of Interest Disclosure}

The author declares that there are no competing interests.

\section{References}

Benner, P., Tanner, C., \& Chesla, C. (2009). Expertise in nursing: Caring, clinical judgment, and ethics (2nd ed.). New York, NY: Springer.

Bergmann, J., Sams, A. (2012). Flip your classroom: Reach every student in every class every day. Washington, DC: International Society for Technology in Education.

Bligh, D. A. (2000). What's the use of lectures? San Francisco, CA: Jossey-Bass.

European Centre for the Development of Vocational Training. (2014). Skill mismatch: More than meets the eye. Retrieved from www.cedefop.europa.eu/files/9087_en.pdf

Freeman, S., Eddy, S. L., McDonough, M., Smith, M. K., Okoroafor, N., Jordt, H., \& Wenderoth, M. P. (2014). Active learning increases student performance in science, engineering, and mathematics Proceedings of the National Academy of Sciences of the USA, 111, 8410-8415. http://dx.doi.org/10.1073/pnas.1319030111

Hartley J., \& Cameron A. (1967). Some observations on the efficiency of lecturing. Educational Review, 20, 30-37. http://dx.doi.org/10.1080/0013191670200103

Jeffries, P. R. (Ed.). (2012). Simulation in nursing education from conceptualization to evaluation (2nd ed.). New York, NY: National League for Nursing.

MacManaway LA. (1970). Teaching methods in higher education-innovation and research. Higher Education Quarterly, 24, 321-329. http://dx.doi.org/10.1111/j.1468-2273.1970.tb00346.x

Mitchell, G. J., Pilkington, B., Jonas-Simpson, C. M., Daiski, I., Cross, N. L., Johnston, N., Peisachovich, E.H., Tang, S.Y. (2016). Nursing education and complexity pedagogy: Faculty experiences with an e-learning platform. Journal of Nursing Education and Practice, 6(5), 60-68. http://dx.doi.org/10.5430/jnep.v6n5p60

Pashler, H. E. (1998). The psychology of attention. Cambridge, MA: MIT Press.

Peisachovich, E, H. (2015a). The importance of intercultural fluency in developing clinical judgment. Journal of Nursing and Health Care, 2(2), 53-59. http://dx.doi.org/10.5176/2010_4804_2.2.77 
Peisachovich, E, H. (2015b). The experience and understanding of clinical judgment of internationally educated nurses. Journal of Nursing Education and Practice, 5(8), 33-43. http://dx.doi.org/10.5430/jnep.v5n8p33

Peisachovich, E. H. (2016a). Succeeding on the Canadian NCLEX-RN: Incorporating experiential learning approaches in the education of internationally educated nurses. Journal of Nursing Education and Practice, 6(7), 101-108. http://dx.doi.org/10.5430/jnep.v6n7p101

Peisachovich, E. H. (2016b). Reflection beyond action: A modified version of the "reflecting" phase of Tanner's Clinical Judgment Model. International Journal of Nursing and Health Science, 3(2) 8-14.

Sherwood, G., \& Horton-Deutsch, S. (Eds.). (2012). Reflective practice: Transforming education and improving outcomes. Indianapolis, IN: Sigma Theta Tau Press.

Stuart, J., \& Rutherford, R. J. (1978). Medical student concentration during lectures. Lancet, 2, 514-516. http://dx.doi.org/10.1016/S0140-6736(78)92233-X

Tanner, C. (2006). Thinking like a nurse: A research-based model of clinical judgment in nursing. Journal of Nursing Education, 45, 204-211.

Wilson, K., \& Korn, J. H. (2007). Attention during lectures: Beyond ten minutes. Teaching of Psychology, 34, 85-89. http://dx.doi.org/10.1177/009862830703400202 